\title{
The Responses of Korean Society during 2015 South Korean MERS outbreak
}

\section{Hyun Sook Jo', Sung Eun $\mathrm{Yi}^{2^{*}}$, Chung Sook Kim³ ${ }^{3}$ Jeong Mo Park ${ }^{3}$, Mi Jin Shin ${ }^{3}$ and Hyang Soon $\mathrm{Oh}^{4}$}

${ }^{1}$ Gachon University, 1342 Seongnam-daero, Bokjeong-dong, Sujeong-gu, Seongnam-si, Gyeonggi-do, South Korea

${ }^{2}$ Aram Nightingale Nursing Institute, 206-1604 Raemianhurest, 860 Hoguk-ro, Dukyang-gu, Goyang-si, Gyunggi-do 10467, Republic of Korea

${ }^{3}$ Kyungin Women's University, 548-4 Gyesan-dong, Gyeyang-gu, Incheon, South Korea

${ }^{4}$ Sunchon National University, Jeollanam-do, Suncheon, Seokhyeon-dong, South Korea

\section{Abstract}

Purpose: The purpose of this study is to find what was the social responses and to identify the failure and weakness in 2015 MERS control in South Korea, and to suggest the strategy for emerging infectious diseases in the future.

Method: The period of data collection was from May 21 2015, when MERS outbreak was reported on ' $\mathrm{H}$ ' offline newspaper for the first time to July 312015 , the day when South Korean government declared the eradication of MERS in the country. The total news items (NIs) collected for the analysis was 457.

Result: There were 895 MERS NIs on the 'H' newspaper and 457 MERS NIs were adopted for this study. There were 462 MERS NIs on epidemiology of MERS, 250 MERS NIs on public health related.

There were 428 MERS NIs related to central and local government. The NIs related to MOHW was 163 NIs.

Other social and cultural issues including hazardous communication and hospital visiting attitude were reported in 270 MERS NIs.

Conclusion: The philosophy and policy of the central government was the key to control emerging infection when the experiences in SARS compared to the MERS cases in Korea. The change of weather pattern was another key point in MERS outbreak in Korea. Also the crowded hospital environment because of relatives and friends visiting the patients was one of the causes of Korean MERS outbreak. Moreover, the public attitudes including hand washing, selfresponsibility and corporation in isolation were also the points to control emerging respiratory infection. For the future in Korea, there have to be a paradigm change in governmental corporation and public like the Taiwan cases.

Keywords: MERS; Emerging infection; Infection control; Public health

\section{Introduction}

After the introduction of penicillin at early 20C, people had begun to think and believe that infectious diseases could be eradicated. However, the belief had to be changed with the emerging of drug resistant micro-organism. Now we cannot eradicate infectious diseases, but only control them. In the battle over infectious diseases, we need to think of the ecological approaches.

In the history, infectious diseases had influenced and changed the society and the way of human life. Plague has changed the history of Western Europe [1], and the Spanish soldiers have been able to conquer the Meso and South America with the epidemic of smallpox [2].

With the emergence of AIDS in 1980s followed by increasing tuberculosis, SARS in 2001, avian influenza in 2003 and H1N1 in 2009, people have confronted with the fact that infectious diseases should be regarded as not just diseases but as societal, economical, political matters, and international diplomatic issues as well [3].

With the pandemic of SARS, many countries including Taiwan and Canada [4] have met big sociological crisis. Especially, Taiwan has met the crisis of collapsing medical and public health system. But South Korea has showed good example in control of AIDS, SARS and avian influenza [5].

However, the public health system of Korea to control emerging infection has been weakened by the domestic political policy. That is, the control tower for emerging infection has been transferred to the director of KCDC (Korean Center for Diseases Control) from the prime minister during the Lee government [6]. With the epidemic of H1N1 in 2009, South Korean government has shown the ineffective control system in medical and public health as well as in public and social aspects. As the result, the mortality rate of H1N1 in South Korea 2009 was the highest among 3 East Asian countries, including Japan and Taiwan [7]. One of the ineffective control practices reported was to have school teachers check the body temperature of every student at the school gate during H1N1 epidemic [7].

The MERS in South Korea 2015 was a shock to all Korean especially to medical care personnel. Before the MERS shock in Korea, most of Korean medical personnel had been proud of the quality of infection control practices in Korea. For example, Korean infection control with SARS has been approved by WHO as excellent [6]. The failure of MERS control especially in a major university hospital has become a serious challenge to Korean medical and public health system.

Furthermore, Korean society has revealed the weak points in some aspects of social system, those were; hazardous communication,

*Corresponding author: Sung Eun Yi, Aram Nightingale Nursing Institute, 206-1604 Raemianhurest, 860 Hoguk-ro, Dukyang-gu, Goyang-si, Gyunggi-do 10467, Republic of Korea, Tel: 82-10-8760-5362; Fax: 82319635362; E-mail: yisungeun@hanmail.net

Received March 03, 2018; Accepted March 14, 2018; Published March 21, 2018

Citation: Jo HS, Yi SE, Kim CS, Park JM, Shin MJ, et al. (2018) The Responses of Korean Society during 2015 South Korean MERS outbreak. Health Econ Outcome Res Open Access 4: 150. doi: 10.4172/2471-268x/1000150

Copyright: @ 2018 Jo HS, et al. This is an open-access article distributed under the terms of the Creative Commons Attribution License, which permits unrestricted use, distribution, and reproduction in any medium, provided the original author and source are credited. 
medicine oriented control rather than the public health system, and none of the public education program for the infection control. In some aspect, we could expect the failure in 2015 MERS control from the experience of ineffectiveness in H1N1 control [7].

The purpose of this article is to find the social responses and to identify what the failure and weakness 2015 MERS control in South Korea are, and to suggest the strategy against the future emerging infection.

\section{Method}

\section{Study objects and period}

Emerging infection brings the influences on every societal aspect, including politics, economy and culture. Newspaper is a conventional channel to understand the society in Korea. Compared to the online newspaper, it is common that the news items (from now on NI or NIs) on offline newspaper are more trustful and reliable publicly. Through analyzing the NIs in newspaper, we can expect to find and understand the societal response to a specific social issue. The data for this study were collected from one of the main newspapers in South Korea.

The tendency of broadcasting and publishing direction of the newspaper is usually based on it's political philosophy. Kim et al. [8] had classified the South Korean newspapers by the type of political tendency; conservatism, progressivism and centrism. Among ten major newspapers, the ' $\mathrm{H}$ ' newspaper was chosen as the representative of centrism oriented mass media [8]. The data and information for this study were collected from the ' $\mathrm{H}$ ' offline morning newspaper.

The period of data collection was from May 21 2015, when MERS outbreak was reported on the ' $\mathrm{H}$ ' offline newspaper for the first time, to July 312015 , the day when South Korean government declared the eradication of MERS in the country. The total number of NIs collected for analysis were 457 pieces.

One researcher collected data from the ' $\mathrm{H}$ ' offline newspaper on daily base through checking all the NIs. All the NIs which includes the term 'MERS' were screened everyday throughout the data collection period. If one NI with MERS term had been found, the NI was checked again on the 'Daum' internet site, one of the main internet sites in South Korea, and brought to the file of the NI and saved for the study data. The NIs not founded in the internet were 4 pieces in total, and those NIs were scanned and filed for the study.

To confirm the representation of the collected data, the NIs with MERS term were retrieved from the ' $\mathrm{H}$ ' newspaper homepage by a researcher. Of the total 8,176 NIs excluding advertisement, 895 MERS NIs were retrieved during data collection period. Of the 895 MERS NIs, the study data set of 457 NIs, $50.1 \%$ of total MERS NIs was collected. The characteristics of missing data were checked by two researchers. Among 438 missing MERS NIs, 252 NIs (57.5\%) were not relevant to the study purpose, and the other NIs (186 pieces) were relevant but duplicated. The mean proportion of the study data set NIs was $5.6 \%$ of the total NIs, and the other missing MERS NIs was $2.3 \%$. The study data set was not statistically different from the total MERS NIs ( $p=0.40$, Figure 1).

The coding instruction for data analysis was developed through three times of researchers meeting. The coding instruction was composed of 16 criteria; general information, type of NIs, and epidemiology, prevention and treatment of MERS, death from MERS, nurse and physician related, KCDC including MOHW (Ministry of Health and Welfare), public health center, school including local ministry of education, parliament, diplomatic issues, economic, other social related information.

In the general information, date of NIs issued, the number of page, title of NI and the internet addresses of the NIs were included. The type of NI was collected through the title of NI, those were news, editorial, reporter column, fixed outsider column, and reader opinion and others. For the qualification of the study data coding, two researchers conducted the coding process for the professionalism and accuracy. Frequency, \%total and t test was adopted for statistical analysis using SPSS version 12.0.

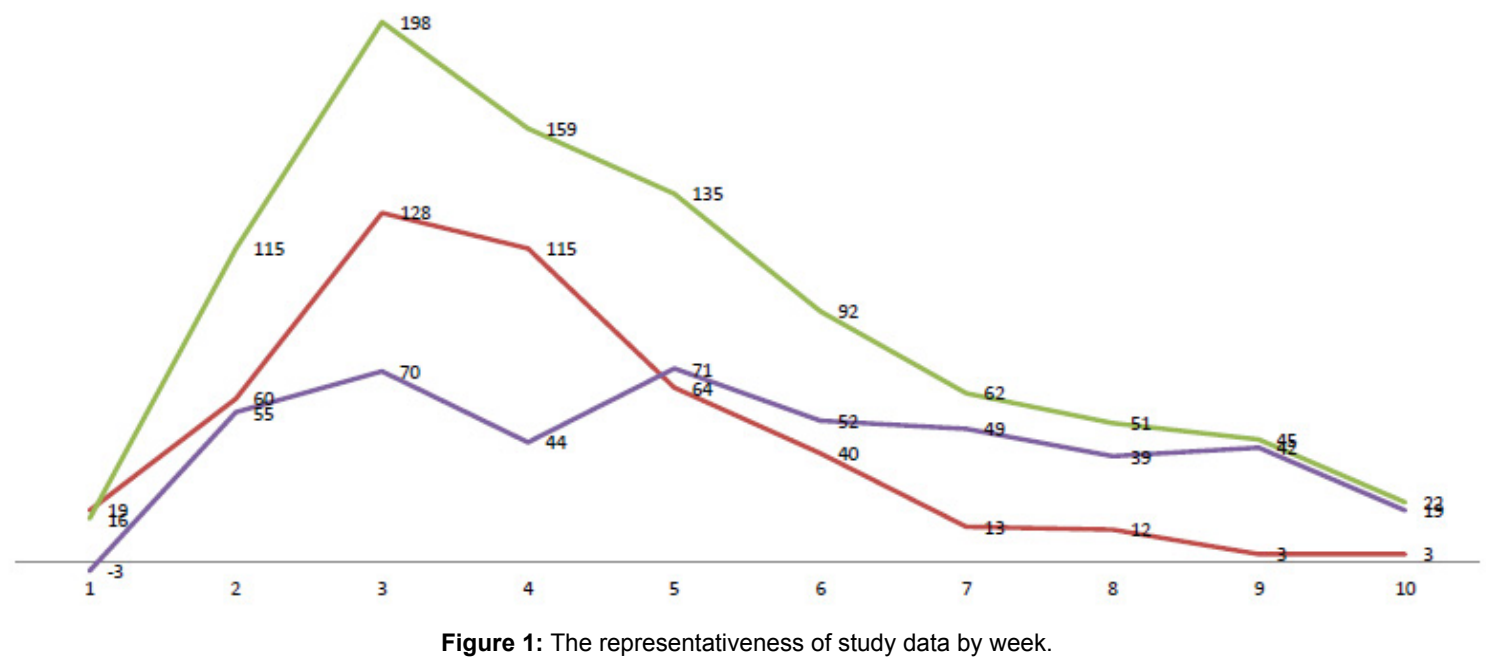


Citation: Jo HS, Yi SE, Kim CS, Park JM, Shin MJ, et al. (2018) The Responses of Korean Society during 2015 South Korean MERS outbreak. Health Econ Outcome Res Open Access 4: 150. doi: 10.4172/2471-268x/1000150

Page 3 of 9

\section{Results}

\section{The general characteristics of MERS NIs during South Korean} MERS outbreak

There were 895 MERS NIs in the ' $\mathrm{H}$ ' newspaper dated between May 212015 and July 312015 . And 457 NIs were adopted for this study. Of them general pure NIs were 362 , editorials 47 , reporter columns 22 , fixed columns 22, reader opinion and others 8 pieces.

During MERS outbreak, the pure NIs were sorted into 8 titles; overall, invasion of MERS dissemination, all-out war for MERS cessation, one month MERS, when will MERS go, education from MERS epidemic and others. The number of pure NIs on invasion of MERS were 80 pieces and all-out war for MERS cessation was 74 pieces. On the 4th week during MERS epidemic, there were $116 \mathrm{NIs}$, the highest number during 10 weeks, and followed by 5 th week. Figures 2 and 3 show the general figure of MERS NIs.

\section{The NIs on epidemiological, publichealth and medical treatment characteristics}

There were 462 NIs on epidemiology of MERS. The most frequent issue on those NIs was about the incidence of MERS (160 pieces), and
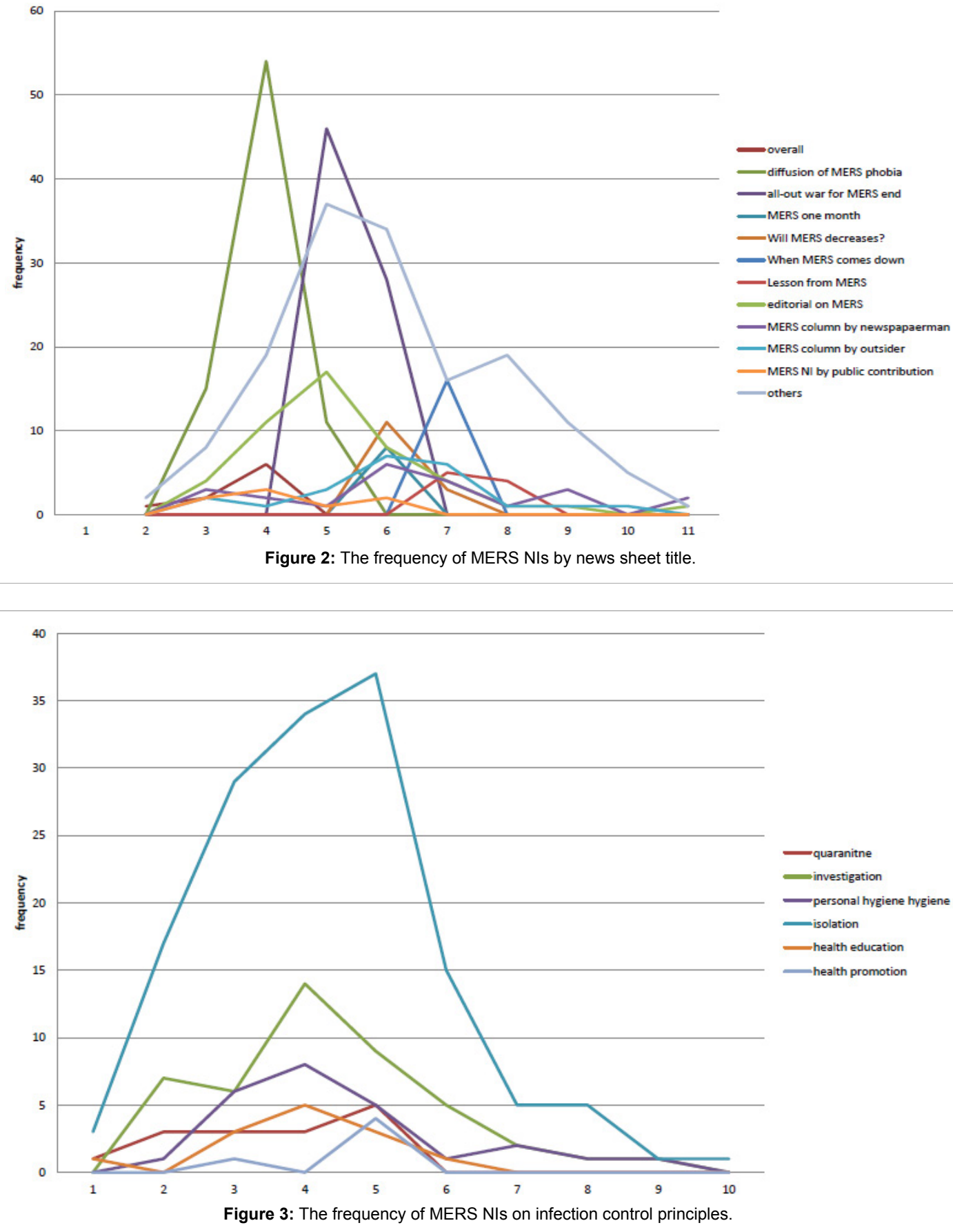
Citation: Jo HS, Yi SE, Kim CS, Park JM, Shin MJ, et al. (2018) The Responses of Korean Society during 2015 South Korean MERS outbreak. Health Econ Outcome Res Open Access 4: 150. doi: 10.4172/2471-268x/1000150

Page 4 of 9

the second issue was about transmission (156 pieces). There were 83 pieces about host. The most frequent issue on host was about signs and symptoms of infected cases. And 19 pieces were about environment (Figure 4).

There were 250 NIs on public health related. The most frequent issue was related to isolation (147 pieces), and next was investigation (45 items). On the 4 th week of epidemic the biggest number of 64 NIs were found, and 63 NIs on the 5th week (Figure 5).

The MERS NIs related to acute care settings were 562 pieces (count duplicated). Also in the 4 th week, the peak number of 171 NIs were shown, followed by the 3rd and 5th week (Figure 6).

\section{MERS NIs related to government, parliament, education system, international affairs and social and cultural issues.}

There were 428 NIs related to the central and local government. The NIs related to Ministry of Health \& Welfare (MOHW) was the top, 163 pieces. The next frequent NIs was on the government organizations excluding MOHW (118 pieces). There were 45 NIs on Korean Center for Disease Control (KCDC). And news items related to the public health center were 26 pieces (Figure 7).

There were 252 NIs related politics, economics and international affairs. The NIs on head of local government were 51 pieces. 46 NIs were on the president Park. Next was on general minister (37 pieces). NIs on national assembly were 35,28 NIs on educational institutions, 14 NIs on Ministry of Education and 14 NIs on local office of education (Figure 8).

The education institutes including individual schools, Ministry of Education, education office and kindergarten was one of the hot issues on MERS media (Figure 9).

NIs on the affect to domestic economy were 103 pieces. NIs related to big scale shopping mall were 23 , local market 11 , and cultural event such as movie theaters 16 pieces. NIs related to communication channel, hospital visiting attitudes, and hazardous communication were 270 pieces (Figure 10).

In international affairs, NIs WHO related were the most frequent; 35 cases. Next was about the decrease in foreign travelers entrances, 32. And international relations such as canceling international academic conferences were 18 (Figure 11).

\section{Discussion}

The governmental philosophy and the control of emerging respiratory infection

During the SARS pandemic 2001, South Korea showed an example of success for controlling the emerging respiratory infection; policy of the central government has opened to the public at reasonable time, and the active communication between government and mass media was the key of the success. The officers of MOHW (Ministry of Health and Welfare) were not afraid of being criticized from mass media. They were eager to provide correct information to the public through mass media. At the beginning stage, mass media and people had blamed at the government policy, however, they have become to understand the situation gradually. Due to the strategy opened at the very beginning of the conflict, South Korean government could make a good defense system to prevent and control SARS [7].

However, in 2009 with the H1N1 pandemic, South Korean government has not shown an effective control system. First problem was appeared with the governmental control tower, differently from the case of SARS. During SARS pandemic, the prime minister was the top of control system, but the head of KCDC was the top during $\mathrm{H} 1 \mathrm{~N} 1$ pandemic. And there was no appropriate cooperation among intra government organizations, lack in power of control system, no system to educate the public, no channel to educate and prepare the medical personnel and no effort against hazardous communication of mass media and public [9]. On comparing the control system with the east Asian countries, South Korea showed failures in several aspects.

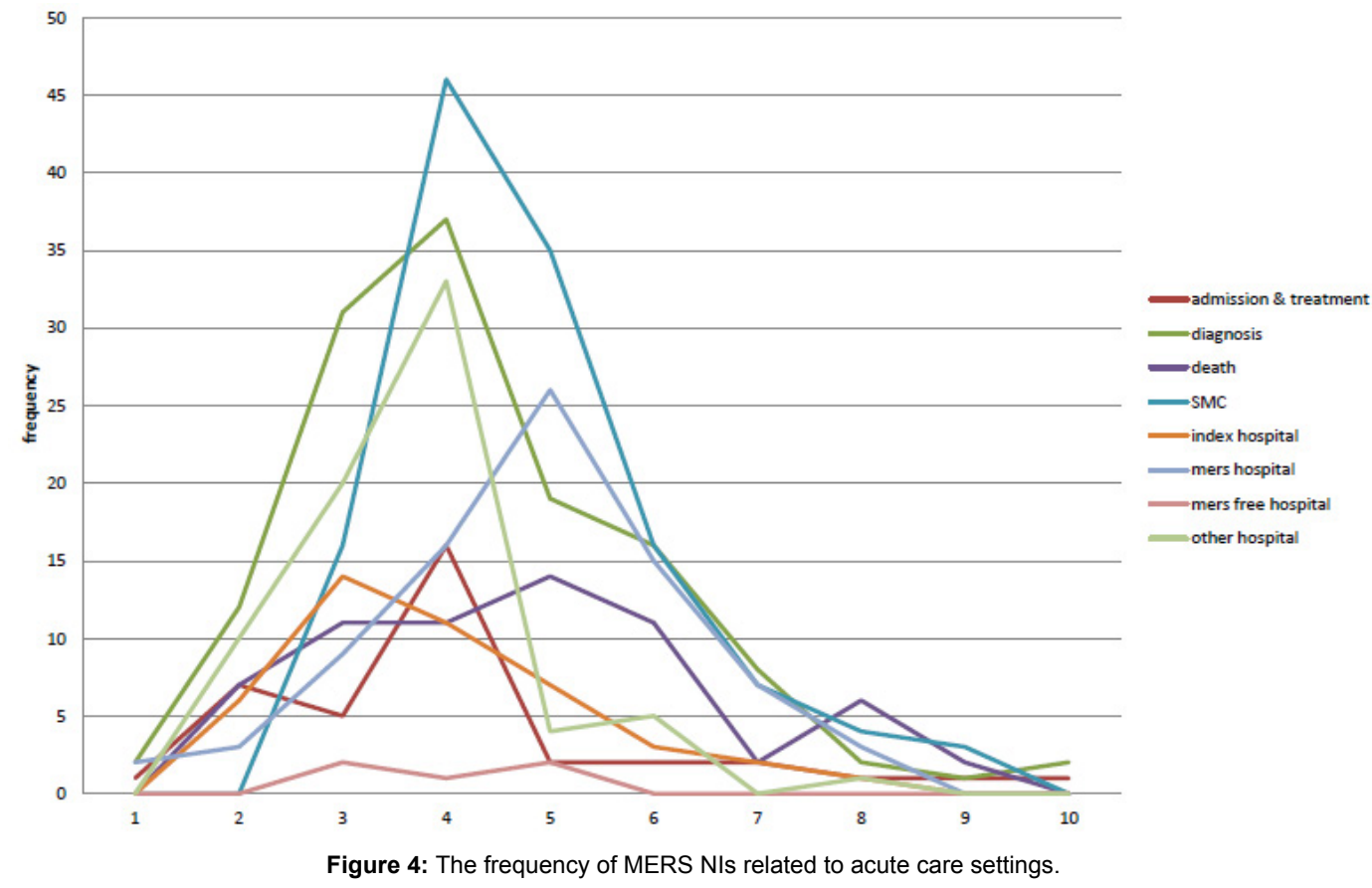


Citation: Jo HS, Yi SE, Kim CS, Park JM, Shin MJ, et al. (2018) The Responses of Korean Society during 2015 South Korean MERS outbreak. Health Econ Outcome Res Open Access 4: 150. doi: 10.4172/2471-268x/1000150
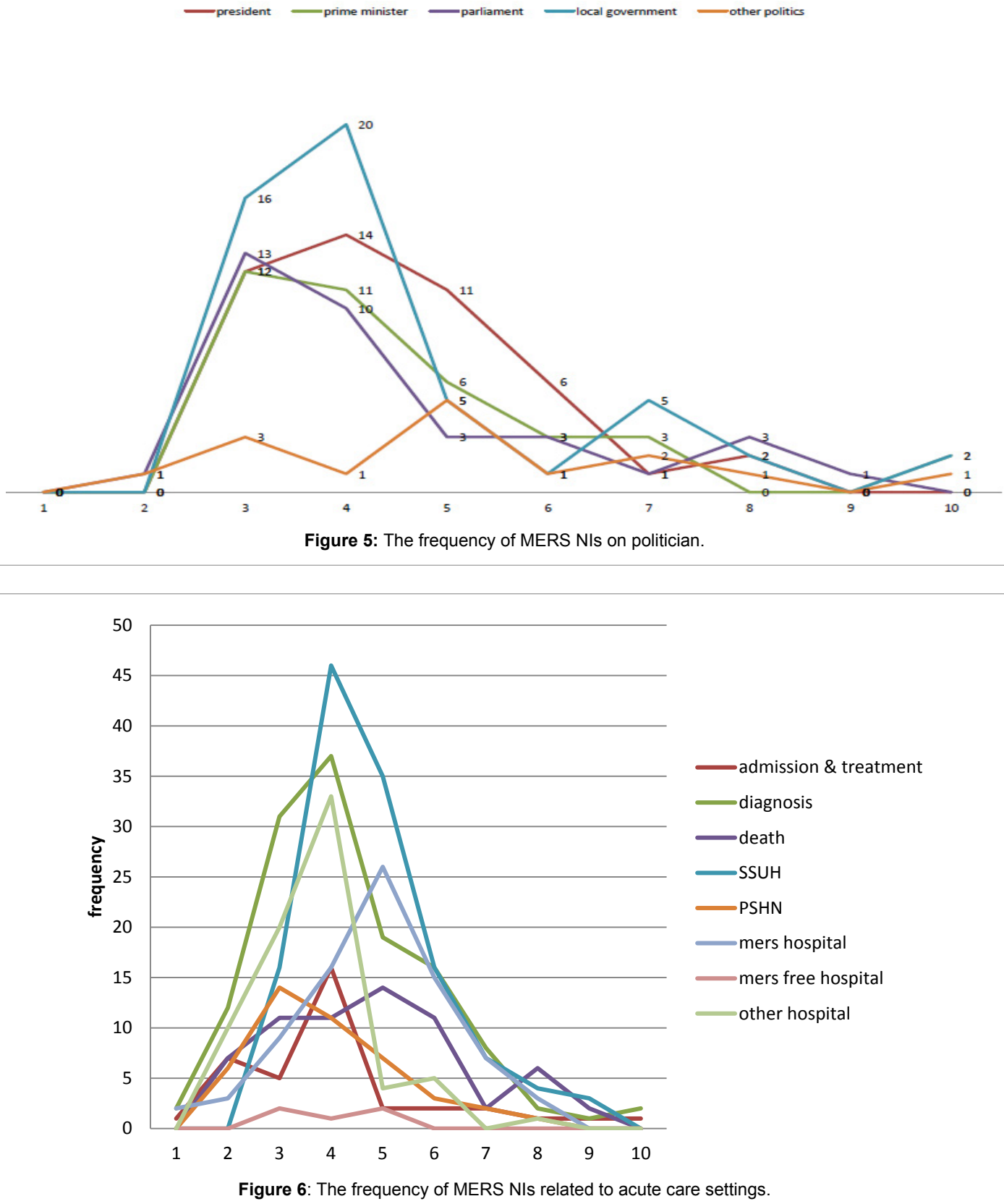

First, South Korea showed the highest mortality rate among 3 countries (Japan and Taiwan). Second, there was no acting guideline before H1N1 invasion. Third, there was no education program for general practitioners and the public.

The Korean MERS chaos was resulted from the governmental systemic weakness shown in H1N1 pandemic 2011. At first, the failure of Korean MERS epidemic was the governmental policy. The KCDC hesitated to open the outbreak of MERS to the public. They missed the first principle guideline of emerging infection control. They hesitated to open the title of source hospital to the public. KCDC confirmed the 3 MERS outbreak on May 21, 2015. With the delayed governmental action, one MERS case from index hospital escaped to SMC emergency room, and it became the ignition point of MERS outbreak in SMC.
No governmental control tower and weak control system, no communication among government organizations and lack of education system for the public seemed to be the weak points to control MERS. For example, some mass media reported that MERS might be transmitted via camel meat. And in the government there was no expert to control the infectious diseases. Moreover, some politicians including the president have confused MERS with influenza [10].

Even though the very beginning stage of epidemic should be the critical time to control of disease transmission, government was not eager to open the information on the infected patients and hospitals. One patient among the first group has transmitted to an university hospital by himself, and it became the trigger of Korean MERS epidemic. The mayor of Seoul Metropolitan leaded the turning point of MERS control. He opened every information (hospital title and 
Citation: Jo HS, Yi SE, Kim CS, Park JM, Shin MJ, et al. (2018) The Responses of Korean Society during 2015 South Korean MERS outbreak. Health Econ Outcome Res Open Access 4: 150. doi: 10.4172/2471-268x/1000150

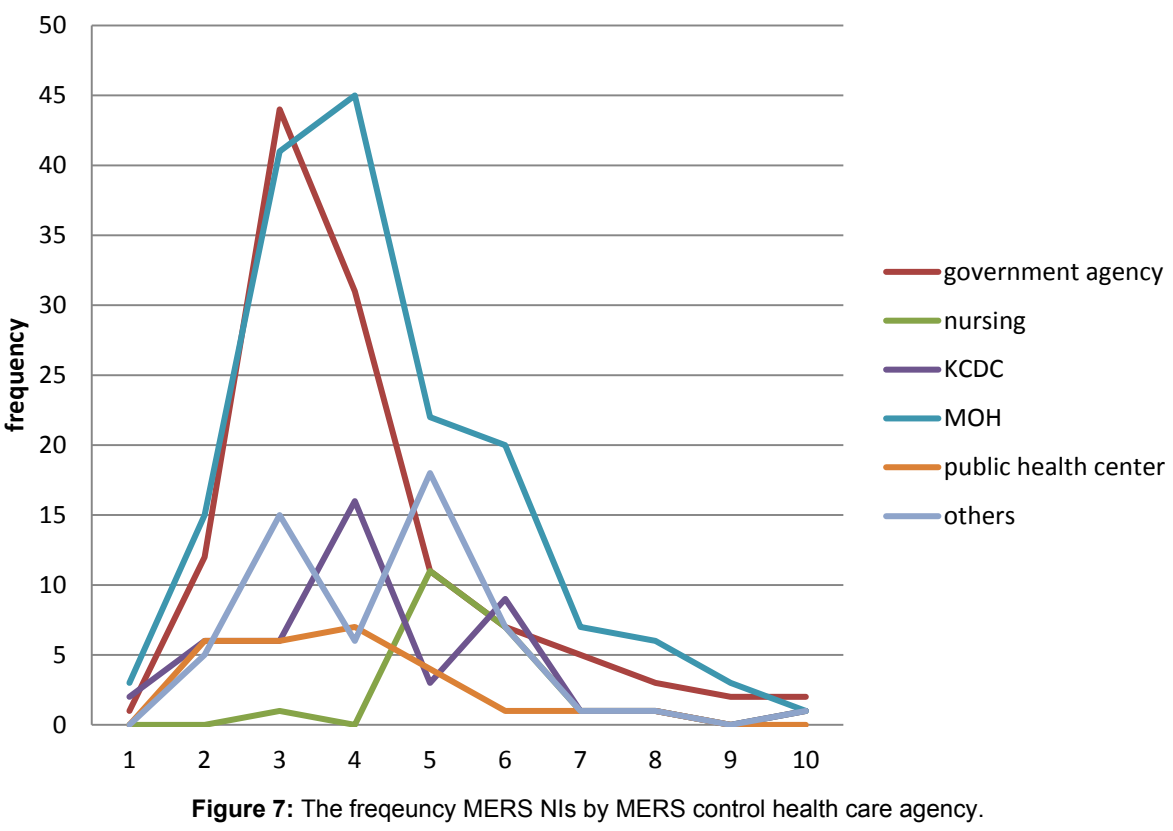

$\longrightarrow$ president $\longrightarrow$ prime minister $\longrightarrow$ parliament $\longrightarrow$ local government $\longrightarrow$ other politics

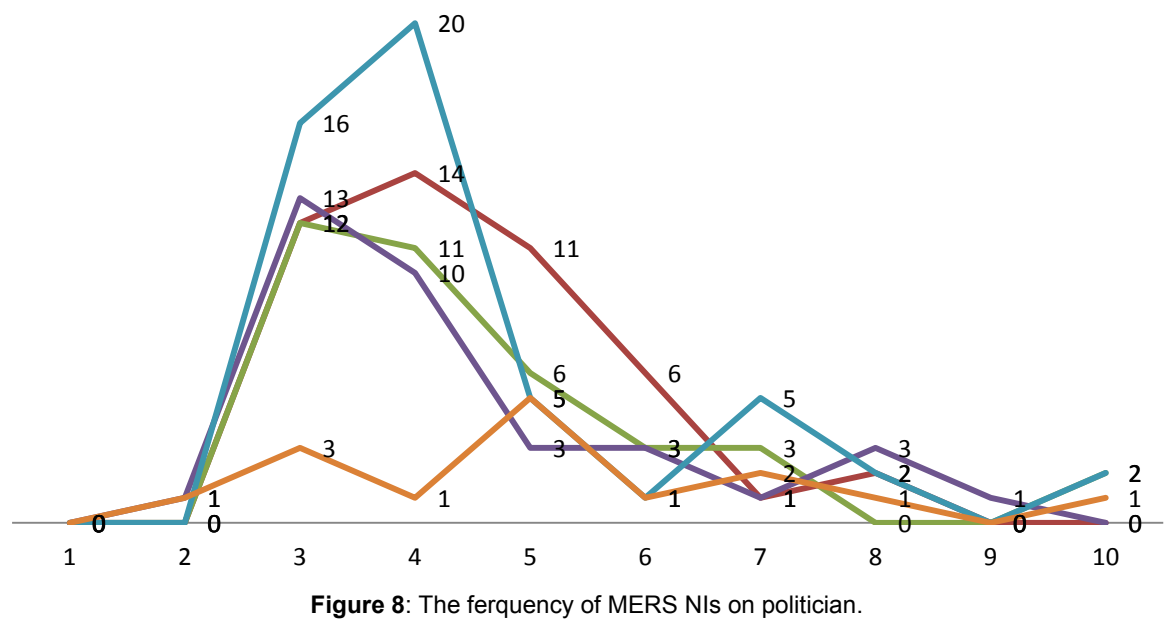

exposure chance pathway from infected patient etc.) to control MERS, and it became the political issues. However, this try induced the attitude change of the central government, and it became the changing point of decrease in epidemic curve.

\section{The South Korean Society and MERS outbreak}

As mentioned above, South Korea showed a good example to control SARS. At that time, KCDC was not organized, and National Institute of Health has played the key control role of SARS. The political tendency of the government was liberal, and the government has paid more attention to the public health, and the minister of MOHW was the top of SARS control. With this system, Korean government could control SARS successfully.
During H1N1 epidemic, the political party on power was conservative one. They have minimized the control system in which the top of the control tower was the head of KCDC, so that the central government control system did not work effectively. When considering the official position of the head of KCDC, it is not a proper official position to manage and control the situations fully. Consequently, South Korea showed three times higher mortality rate compared to that of Japan and Taiwan, and also revealed many problems in hospitals and schools.

President Park's government was also a conservative political party, they showed very little attention to the public health. There was no public health secretary for the president and the president was confused MERS with influenza. When President Park has visited one 
Citation: Jo HS, Yi SE, Kim CS, Park JM, Shin MJ, et al. (2018) The Responses of Korean Society during 2015 South Korean MERS outbreak. Health Econ Outcome Res Open Access 4: 150. doi: 10.4172/2471-268x/1000150

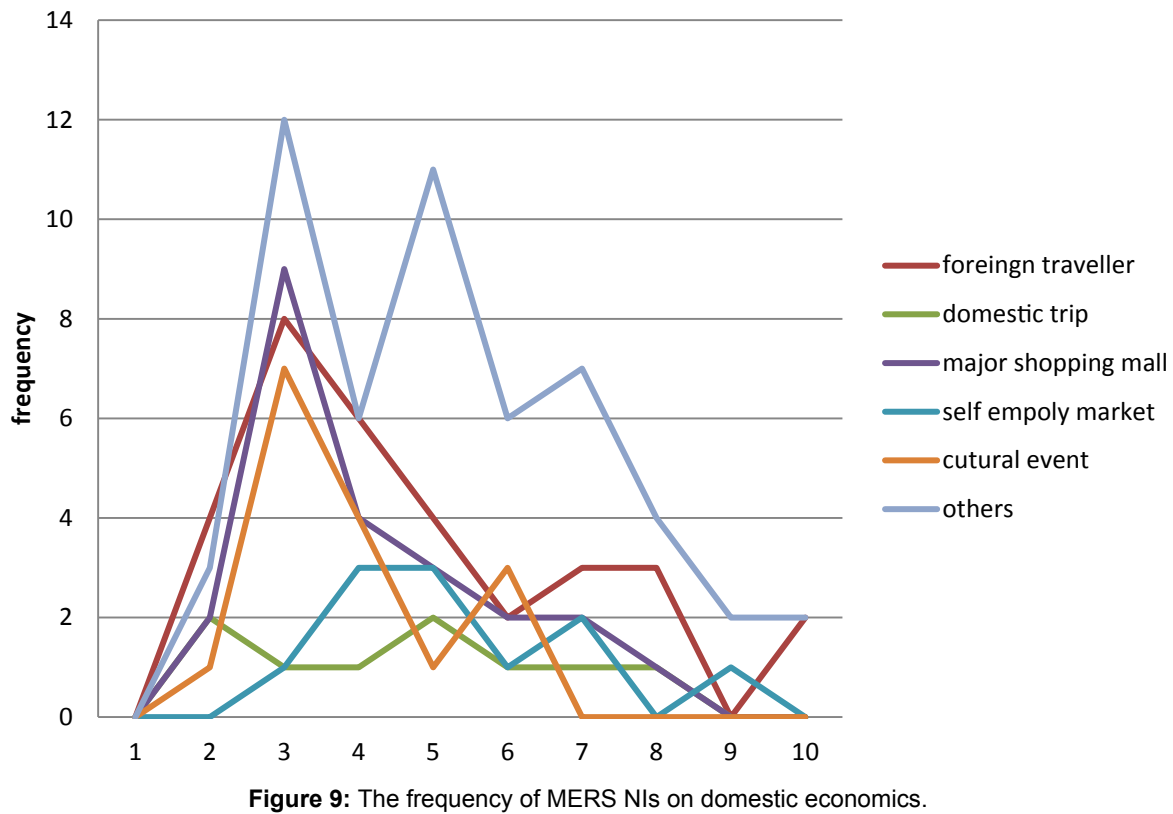

ministry of education $=$ education office $=$ school $=$ kindergarden

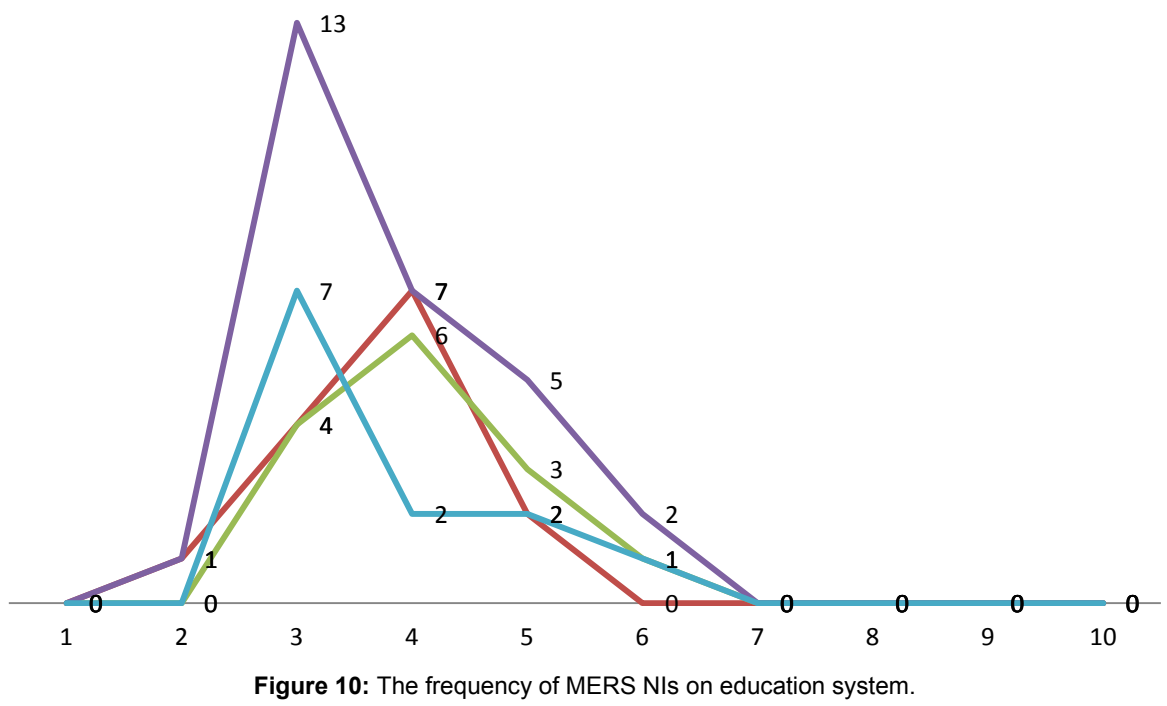

primary school during MERS pandemic, she talked to the students, "Do not worry, MERS is just a influenza from the middle east" [10].

\section{MERS outbreak and South Korean infection control attitude}

Before western style hospital system has been introduced to Korea at the end of 19 century, there was no system hospital like in Korea. During the Japanese colonial, western style hospitals were introduced to Korea by some missionary funds. At that time the level of Korean life was very poor, and the setting of the hospital was much superior to the level of ordinary Korean life. From the middle of 1990s with economical success and settlement of national health insurance, the well-funded general hospitals tried to serve well designed and decorated interior environment, Korean people had no reluctance to visit the hospital. On the contrary, visiting famous general hospitals became a picnic like life style among Korean people. The cases that many hospital visitors were infected with MERS tell us the situation of Korea. High occupancy rate of bed also tells us how crowded in famous general hospitals in Korea.

Korean showed extreme responses in two ways at infectious diseases control. One is panic and hysterical response that we could see at the case of mad cow disease controversy in 2008. That was a social hysterical response.

The other was the insensibility at the first stage quarantine of MERS. All the contactors to infected patient were recommended to stay home isolated from any contacts. However, one infected woman traveled to the other province more than $200 \mathrm{Km}$ away from her residence for golfing. 


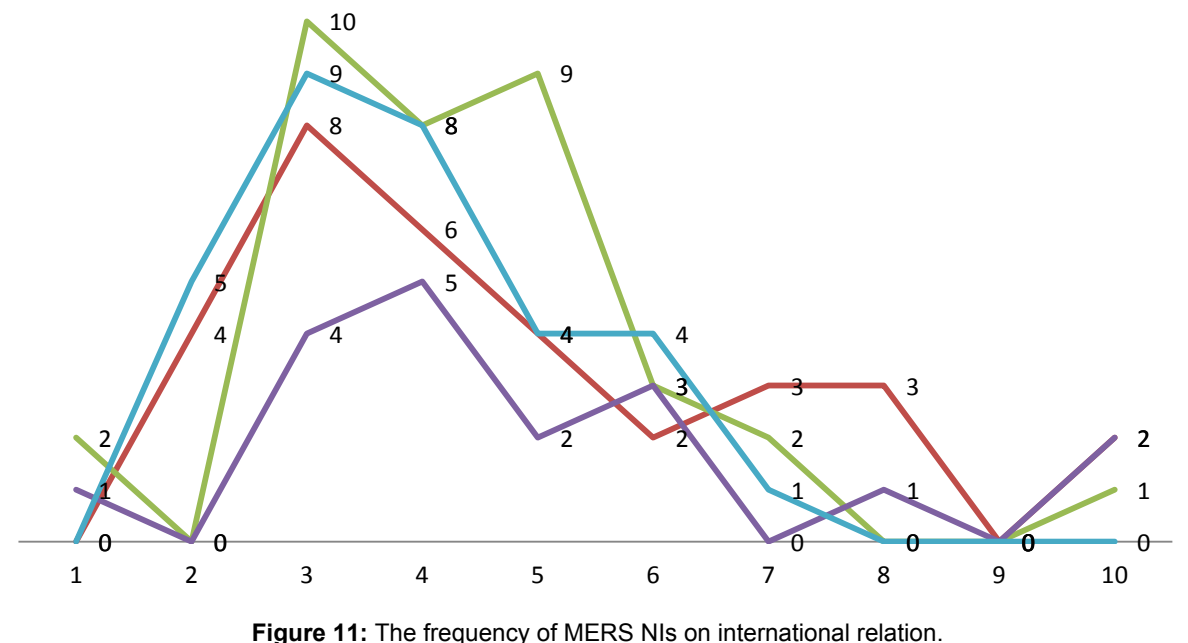

After that stage, the phobic hysteria stage was appeared. There was a mass of discrimination for the medical personnel and their family members. During medical personnel met a big challenge at work, and also their family met difficulties of discrimination from their neighbors [11].

Those responses could be induced by lack of communication and education to the public for infectious diseases. Anyone could be a victim of infectious diseases, and also could be an assailant with an infectious disease in these situations.

Political populist also played a role in this situation. The government paid little attention to educate the people for prevention, rather paid more attention to treatment.

Historically Korean did not have experienced worse cases than the case that western countries experienced like plague in medieval times. Therefore, the level of Korean habitual way of sanitation and hygiene is not so high compared to that of western countries. For example, you might see in public toilet there are many people who don't wash their hands after using toilet, and still they share big bowel soup together using individual spoon.

The causes of 2015 South Korean MERS epidemic should be fully investigated in every social context. By the KCDC official report of 2015 MERS OUTBREAK in ROK; "Learning from MERS", the Korean MERS should be controlled by traditional basic precaution practice not high technology medicine, and there was systematic blocking the public health organization and shortage of manpower both in quantity and quality [12].

Except the index general hospital and one university hospital, the level of infection control were quite good in most general hospital. However, the culture of visiting patients in hospitals has been as a big issue for further control.

\section{The weather and MERS}

The pattern of 2015 Korean MERS transmission was so rapid, and showed high infectivity and pathogenicity at the beginning stage of outbreak, as found in the case of increasing pattern. Here we need think about the climate condition.
The weather in South Korea during MERS outbreak was very dry compared to the previous year and following year. The average precipitation in May is $101.7 \mathrm{~mm}$ contrast to $56.5 \mathrm{~mm} \mathrm{(51 \% )} \mathrm{in} \mathrm{May}$ 2015. The average temperature across the country in May is $17.2^{\circ} \mathrm{C}$, but in May 2015 it was 18.6. It ranked the top since 1973 [13].

It seemed very small amount of MERS virus induced infection and developed the symptoms during Korean MERS outbreak. Also dryness of upper respiratory system helps virus inoculation to respiratory mucosa.

MERS virus is very strong with dryness, and alcohol also help dryness [14], and we can think the alcohol gel antiseptics for hand washing may not effective against MERS virus when hands are contaminated severely, because it could induce dryness of skin before it kills the MERS virus. We need more experimental study for the antiseptics and other disinfection and sterilization.

\section{Conclusion}

457 MERS NIs from the offline ' $\mathrm{H}$ ' newspaper from May 21, 2015 to July 31, 2015 were analyzed for this study. The first MERS case was reported on May 21, 2015 and the cessation of MERS case was declared by South Korean government on July 312015.

There were 895 MERS NIs from the ' $\mathrm{H}$ ' newspaper, and 457 MERS NIs were adopted for this study. There were 462 MERS NIs on epidemiology of MERS, 250 MERS NIs on public health related.

There were 428 MERS NIs related to central and local government including 163 MERS NIs related to MOHW.

Other social and cultural issues including hazardous communication and hospital visiting attitude were reported at 270 MERS Nis.

The philosophy of central government was appeared as the key to control the emerging infection from the experience of SARS and MERS in Korea. For prevention and control infectious diseases, cost effective and medical oriented approach should not be the first choice.

The change of weather pattern was another key point in MERS outbreak in Korea. Also the crowded hospital environment was one of 
Citation: Jo HS, Yi SE, Kim CS, Park JM, Shin MJ, et al. (2018) The Responses of Korean Society during 2015 South Korean MERS outbreak. Health Econ Outcome Res Open Access 4: 150. doi: 10.4172/2471-268x/1000150

the causes of Korean MERS outbreak. Lastly the attitude of the public was an important factor for controlling the emerging respiratory infection including washing hand, self regulation and isolation. For the future, it is required to change the paradigm in government and public like the Taiwan's experience [4].

\section{Reference}

1. Cantor NF (2001) In the Wake of the Plague The Black Death and the World It Made. The free Press. A division of Simon and Schuster Inc, New York References.

2. Kim JS, Ko MJ (2001) The role of epidemiology against emerging and reemerging diseases. Epidemiology and Health 23: 1-22.

3. Hsieh YH, Chen CWS, Hsu SB (2004) SARS outbreak, Taiwan, 2003. Emerging Infectious Diseases 10: 201-206.

4. Varia M, Wilson S, Sarwals S, McGeer A, Gournis E, et al. (2003) Investigation of a nosocomial outbreak of severe acute respiratory syndrome (SARS) in Toronto, Canada. CMAJ 169: 285-292.

5. Daum encyclopedia (2017) SARS

6. Lim SH (2015) Appropriate preemptive measures against SARS of the government. Hankookilbo.
7. Lee JY, Yi SE, Kanagawa K, Wang R, Sally CWC (2011) Actions against MERS of the front health and medical institutions - Focused on asian 4 countries Korea, Japan, Taiwan, Singapore. The Korea Centers for Disease Control and Prevention (KCDC). Unpublished report.

8. Kim KY, Kim DS, Kim MS, Son SB, Choi JY (2013) 2013 Top 10 daily news papers assessed by yonsei university alumni. The Yonsei Chunchu.

9. Cho MK (2015) Results of R\&D investment for rapid counter measure against Infectious diseases. Cookey News.

10. Choi MS (2015) President Park visited the school re-opened; No need to fear MERS when the health habit kept. Hankookilbo.

11. Korean Association of Infection Control Nurses(KAICN) (2010) Case of H1N1 experience by infection control nurses in South Korea, Seoul 147-165.

12. MOHW (Ministry of Health and Welfare) (2017) The 2015 MERS Outbreak in the Republic of Korea: Learning from MERS. MOHW Information 11: 135200001644-01.

13. Korea Meteorological Administration (KMA) (2015) Wheather Charecteristics May 2015. News Wire.

14. CDC (2015) Interim Infection Prevention and Control Recommendations for Hospitalized Patients with Middle East Respiratory Syndrome Coronavirus (MERS-CoV). 